\title{
Subject Index to Volume 37
}

A

Age

father's, 127

gestational, 47

mother's, 127, 321, 339

Âland islanders, 277

Analgesia, regional, 331

Anastomoses, 229

Attitude, psychological, 151

Australia, 119, 313, 321

\section{B}

Bed rest, 19, 55

Bereavement, 173

Bias, 217

Birth order, 127, 161, 339

Birthweight, 27, 31, 41, 47, 55, 65, 89,331

Breast cancer, 263

Breech, 331

C

Cancer, breast, 263

Care cost of, 1 neonatal, 27 perinatal, 193

Cesarean section. 11, 31, 65, 77, 105, 239 elective, 99
Child loss, 181

Chorion, 229

Collaborative study, 111

Congenital malformations, $27,111,321$

Conjoined twins, 111, 339

Consanguinity, 347

Contraception, 119

Cost of care, 1

D

Delivery, 89

mode of, 11

preterm, 31

twin, 31

vaginal, 11

Demography, 143

historical, 249

Dermatoglyphics, 199

Development, infant, 81

Diagnosis, maternal, 187

Difference mothod, 299

Differences, individual, 205

Drugs, fertility, 65

Dutchmen, 277

E

EEC-like syndrome, 347

Epidemiology, 277 
384 Subject Index

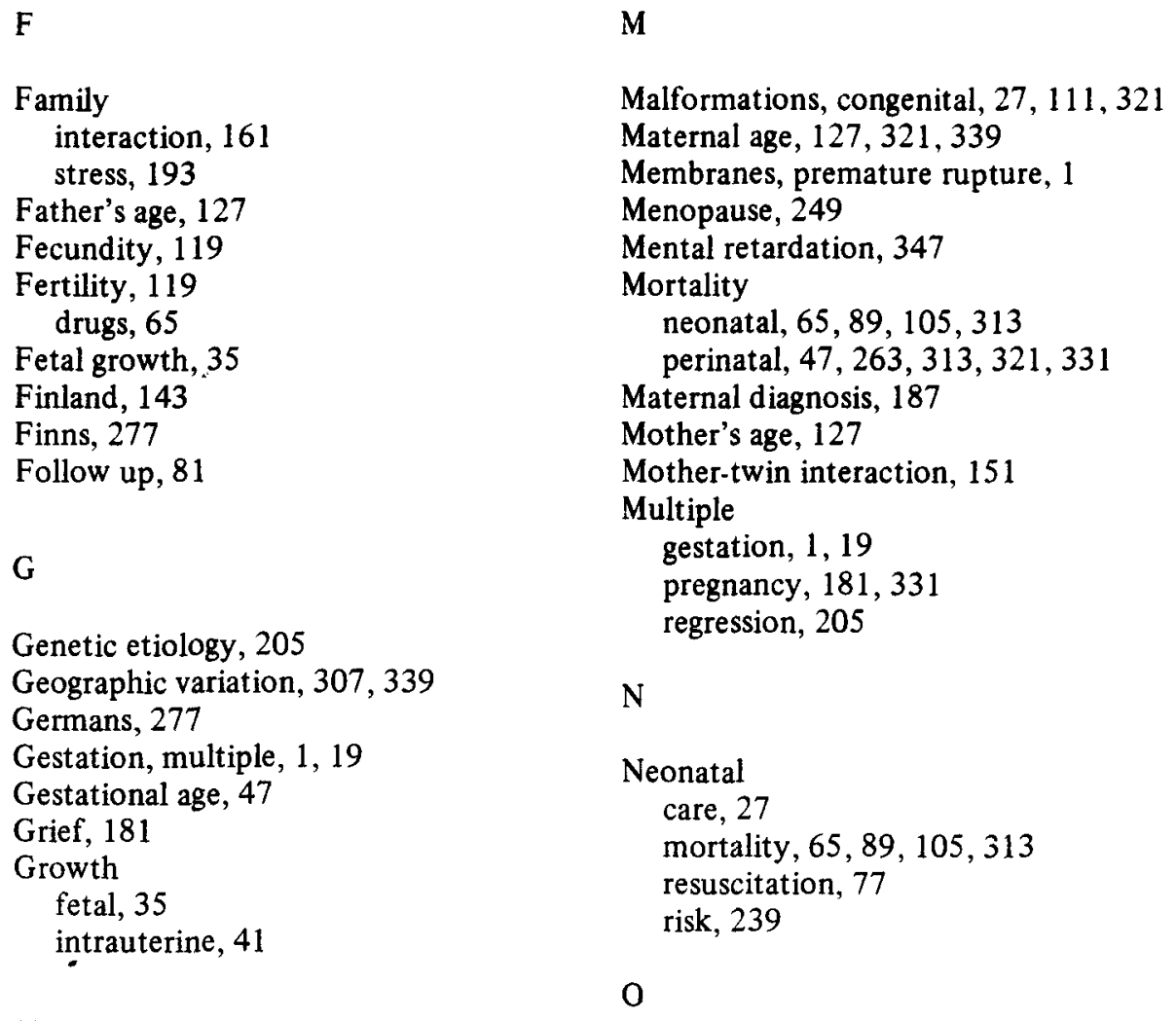

\section{$\mathrm{H}$}

Ovulation induction, 137

Height of women, 263

Heritability, 205

Historical demography, 249

I

Individual differences, 205

Induction, ovulation, 137

Infant

development, 81

preterm, 239

Interaction

family, 161

mother-twin, 151

L

Labor, preterm, 1

Longitudinal studies, 217

Loss, child, 181

$\mathbf{P}$

Perinatal

care, 193

mortality, 47, 263, 313, 321, 331

Personality, 161

Placenta, 229

Population study, 137

Pregnancy

management, 183

multiple, 1, 19, 181, 331

triplet, 99

twin, 47, 187

Prematurity, 55, 81, 331

Preterm

delivery, 31

infant, 239

labor, 1

Privation, 277

Psichological attitude, 151 
$\mathbf{R}$

Rates

response, 217

twinning, 127, 143, 263, 277, 307

Regional analgesia, 331

Regression, multiple, 205

Response rates, 217

Retardation, mental, 347

Risk

factors, 11

neonatal, 239

S

Seasonality, 339

Secular trend, 119

Selection, 217

Sex, 321

Social services, 193

Starvation, 277

Stillbirth, 313, 321

Stress, family, 193

Study

collaborative, 111

longitudinal, 217

population, 137

Swedes, 277

T

Temperament, 239

Temporal variation, 307

Trend, secular, 119

Triplet frequency, 299

zygosity types, 299
Triplets, $41,55,65,77,89,105$

Twin

delivery, 31

pregnancy, 27, 35, 47, 187

register, 27

Twinning, 119, 249, 321 rates, $127,143,263,277,307$

Twins, 11, 41, 137, 151, 161, 173, 193, $205,217,229,239,313,347$

conjoined, 111,339

U

Ultrasound, 19, 35, 331

Upbringing, 151

V

Variation

geographic, 307, 339

temporal, 307

W

Weight, 161

birth, $27,31,41,47,55,65,99,331$

placental, 41

Weinberg's rule, 137

$\mathbf{Z}$

Zygosity, 27, 35, 229

determination, 19, 137

triplet, 299 